EESTI NSV TEADUSTE AKADEEMIA TOIMETISED. XIII KÖIDE

FOUSIKA-MATEMAATIKA- JA TEHNIKATEADUSTE SEERIA. 1964, NR. 1

НЗВЕСТИЯ АҚАДЕМИИ НАУК ЭСТОНСКОИ ССР. ТОМ ХІІ

СЕРИЯ ФИЗНКО-МАТЕМАТИЧЕСКИХ И ТЕХННЧЕСКИХ НАУK. 1964, № I

\title{
РАЗРАБОТКА ГАЗОХРОМАТОГРАФИЧЕСКИХ МЕТОДОВ ДЛЯ АНАЛИЗА ТЕРПЕНОВЫХ ОКСИПРОИЗВОДНЫХ
}

\author{
К. ЛЭЭТС, \\ кандидат химнческих наук
}

\section{A. ЭРM}

Быстро развивающаяся хнмня соедннений тергенового ряда выдвинула важную задачу анализа этнх веществ. Поставленная задача веська сложна, так как, с одной стороны, упомянутые вещества блнзки по своему строенню н свойствам, что затрудняет их разделение, а, с другой стороны, они, даже в мягких условнях, способны изомеризоваться или претерпевать какне-либо другие изненения. Газохронатографическнй метод, дающий возможность точно н быстро проводить анализ смесей этих соелннений, неолнократно прнменялся для анализа терпенов и их пронзводных. В работах Бернарда ['], Янака и Цвркала [2], Лнберти [3] н других $\left[{ }^{4}-7\right]$ анализы терпеновых углеводородов также были проведены этим же методом. Байер [8], Нав [], Доманж и Лонгевелле $\left[{ }^{10}\right]$ проводили газохроматографическим методом анализы терпеновых окснпронзводных, встречающнхся в природных эфнрных маслах.

Определены некоторые нзопреноидные спирты $\mathrm{C}_{15}[11-13]$, а также продукты разлнчных характерных реакций для терпенов: нзомеризацин $\boldsymbol{\alpha}$-пннена $\left[{ }^{14}\right]$, дегидратации ф-терпннеола $\left[{ }^{15}\right]$ и линалоола $\left[{ }^{16}, 17\right]$, циклизацин различных терпеновых пронзводных $\left[{ }^{18}\right]$.

Прн аналнзе соединеннй терпенового ряда газохроматографнческим методом в качестве стационарной фазы обычно нспользуются: Апнезон ( $M$ н $L$ ), силиконовые смазки $(D C-550, E-301)$, полиэфиры двухосновных кнслот с гликолямн, полиэтиленгликоль н т. д. В качестве твердой стацнонарной фазы нспользуются инертные патентованные носители: «Хромосорб W», «Эмбасел», целит 545 , огнеупорный кирпич $C-22$ и другие. Об использованин отечественных матерналов для этих целей нмеются лишь еднничные данные $\left[{ }^{18}\right]$.

Прн нсследовании прнменимости газохроматографнческого метода для аналнза смесей терпеновых оксипронзводных было выяснено, что результаты анализов в сильной степени зависят от конструкцин применяемого прибора (в частности от конструкцнн нспарителя и рабочей температуры колонки), природы актнвной поверкности твердого носителя и способов нанесения стацнонарной фазы на твердый носитель.

Проведенные нами исследовання показали, что полностью ннертным носителем в отношеннн терпеновых оксипроизводных является носитель «Хромосорб́ $W$ » на кютором не наблюдается прнзнаков разложення анализнруемых продуктов при рабочей температуре до $200^{\circ} \mathrm{C}$ (температурный предел прнменяемости жидкой фазы - полиэтнленглнколя 4000). Носитель «Хромосорб $W$ не требует предварительной обработки.

При нспользованин диатомнтового кирпнча Апрелевского завода н носителя

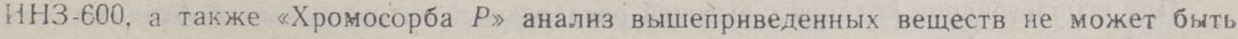
проведен нз-за нх полного разложення на этих носителях. Авторами была разработана нетоднка дезактивацни этих носнтелей, заключающаяся в многократной обработке мв- 
тернала кипящей концентрированной соляной кислотой с последующим его подщелачнванием раствором едкого калия.

Результаты определений показали, что приготовленные таким образом насадки являлись вполне инертными прн их использовании до температуры $180^{\circ}$. Это позволнт расширить ассортимент твердых носителей для газӧхроматографии терпеновых окснпронзводных н дает возможность использовать отечественные материалы.

При определении применяемости твердых носителей в качестве жидкой неподвиж:вой фазы был использован полиэтиленгликоль 4000, вполне инертный к анализируемым веществам.

Как показали исследования, для получения удовлетворительных результатов анализа, другие жидкие фазы (типа полиэфиров двухосновных кислот с диолами), до нанесения на твердый носитель, должны быть предварнтельно нейтрализованы.

Авторами было установлено, что определяемые вещества, в зависимости от условий их испарения, могут претерпевать изменения во время анализа. При этом на изменение веществ могут оказать влияние материал и температура камеры впрыскивания. Из-за последних причин не могут быть использованы для анализа терпеновых оксипроизводных приборы конструкции УХ-1 в условиях более высоких температур. Кроме прибора УХ-1 были проведены исследования на приборе Хром-1. Для получения удовлетворительных результатов на этом приборе необходимо было усовершенствовать конструкцию его камеры впрыскивания, чтобы обеспечить контроль и регулнрованне ее температуры.

Большая чувствительность последнего прибора позволила решить задачу создання высокоэффективньіх колонок для анализа сложных смесей терпеновых производныя, получаемых, например, при реакцин изопрена с уксусной кнслотой [19].

В результате данного нсследования выяснено влияние различных посторонних факторов на результаты анализа терпеновых оксипронзводных газохроматографнческнм методом. Для проведения данного анализа разработана методика и создана аппаратура, исключающие искажающее действие этих факторов.

\section{Экспериментальная часть}

В качестве анализируемых веществ использовались технический гераннол и лнналоол нз природного сырья, предварительно очищенные точной ректифнкацней, н сннтетическнй цитраль, получаемый прн реакции Соммле нз геранилхлорида - основного продукта реакции теломеризашии изопрена с его гидрохлоридами [20].

Газохроматография приведенных веществ изучалась на приборе УХ-1, нзготовленном Таллинским заводом измерительных приборов, и позже на приборе Хром-1, выпущенном заводом «Лабораторне Пристрое» (Чехословакия).

Прнбор УХ-1 снабжен детектором теплопроводности (катарометром), скорость потока газа-носителя определяется при помощи измерителя с мыльной пленкой. Прибор снабжен испарителем из нержавеющей стали, конструкция которого, однако, не обеспечнвает контроля и регулировки температуры камеры впрыскивания, поэтому требуется осторожность при анализе чувствнтельных к перегреванию веществ. Напрнмер, при рабочей температуре колонки $170^{\circ}$ в выключенном испарителе температура быля более $220^{\circ}$ (определено в нерабочем положении). При повышении рабочей температуры колонки, с включением дополнительного нагрева испарителя, а также при про веденни анализов сразу после достижения рабочей температуры колонки (подогрев с максимальным напряжением) наблюдается разложение гераниола и линалоола в исі1арнтеле (рис. 1a), о чем свидетельствует факт, что после стабилизации температуры прн $170^{\circ}$ без дополнительного нагрева испарителя на хроматограмме не обнаружено продуктов разложения этих же веществ (рис. 16).

При нспользовании колонок с высокой разделяющей способностью необходимо про. вести анализ при более высокнх температурах для уменьшения времени удерживания компонентюв. Одновременно время удержнвания может быть сокращено уменьшеннем 


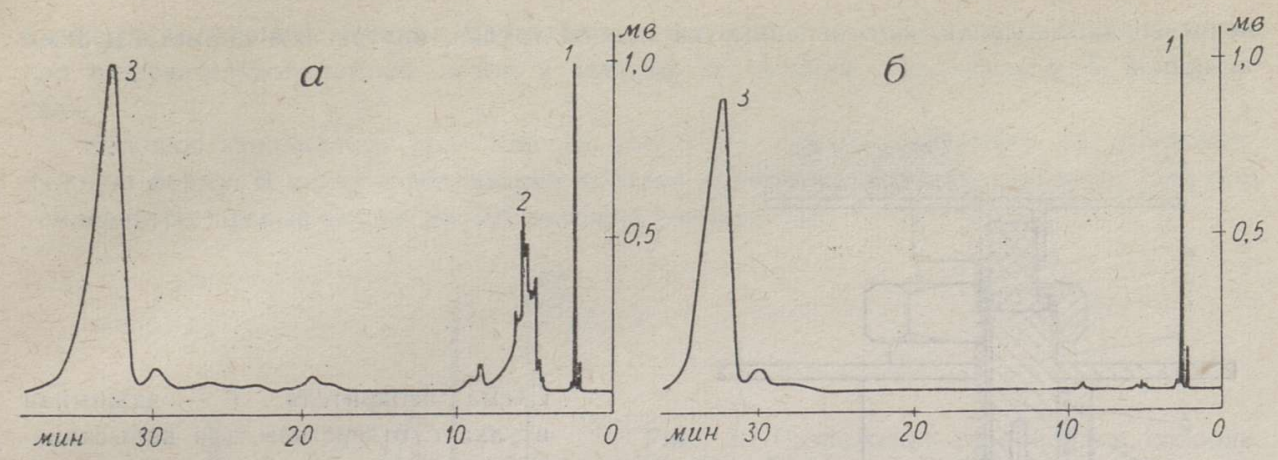

Рис. 1. $a$ - Разложенне гераниола в испарителе прибора УХ-1. 6 - Хроматограмма гераниола после стабилизации температуры испарителя прибора УХ-1.

$T=170^{\circ}$, колонка $15 \%$ ПЭГ на ИНЗ-600, скорость потока водорода 30 мл/мин, вели чнна пробы 0,015 мл; 1 - воздух; 2 - продукты разложения; 3 - гераниол.

количества жидкой фазы на носителе. На приборе УХ-I первое условие не может быть выполнено из-за перегревания испарителя. Уменьшение жидкой фазы на носителе при использовании прибора УХ-1 также не может быть осуществлено, так как это требует введения меньшей пробы, количество которой лимитируется чувствительностью детектора, в данном случае катарометра. По вышеуказанным причинам использование высокоэффективных колонок для анализа терпеновых оксипроизводных на прнборе УХ-1 невозможно.

Лучшие результаты были получены на приборе Хром-1. Прибор снабжен пламеннононизационным детектором, обеспечиваюшим высокую чувствнтельность прибора Однако заводской испаритель не обеслечивал быстрого испарения пробы (рис. 2a), так-
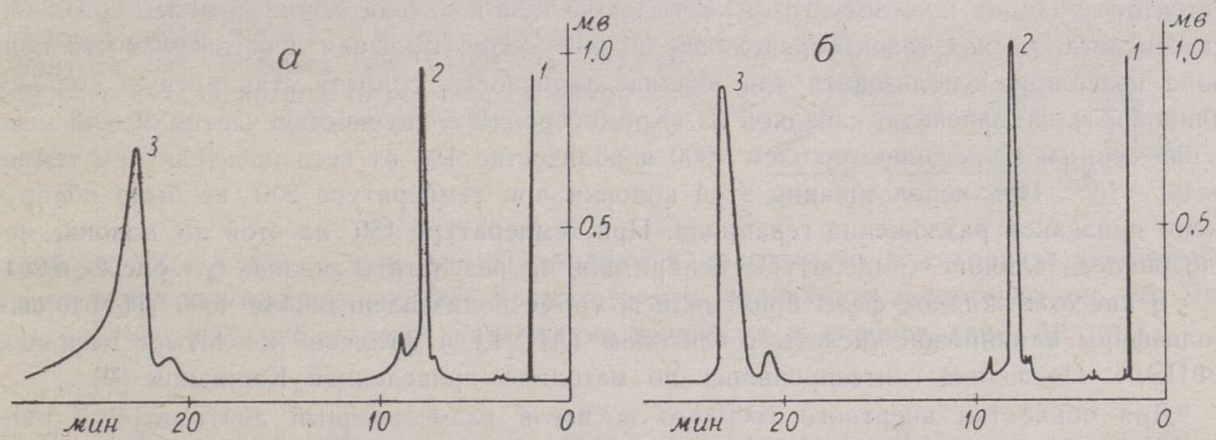

Рис. 2. $а$ - Хроматограмма смеси гераниола с линалоолом на приборе Хром-1 с испарителем заводсиого изготовления. $б$ - Хроматограмма смеси гераниола с линалоолом на приборе Хром-1 с новым испарителем. Температура испарителя $220^{\circ}$.

$T=150^{\circ}$, колонка $4 \%$ ПЭГ на «Хромосорбе $W »$, скорость потока аргона $15 \mathrm{~m} /$ мин, величина пробы 0,002 мл; 1 - эфир; 2 - линалоол; 3 - гераниол.

же не-контролировалась температура испарителя. После усовершенствования конструкцин испарителя по приведенной схеме (см. схему) стали возможными контроль и регулнрование температуры камеры впрыскивания. Было выяснено, что при температуре в нспарителе от 160 до $220^{\circ}$ происходит быстрое испарение пробы без заметного разложения (рис. 2б). При повышении температуры испарителя до $250^{\circ}$ получается хроматограмма, аналогичная хроматограмме на рис. $1 a$, полученной на приборе УХ-1,

Так как колонки прибора Хром-1 заводского изготовления (U-образные, диаметром 8 мм, обіцей длиной $3.4 \mu$, из нержавеющей стали) не могли обеспечить нужное разделенне нсследуемых смесей, и на внутренней поверхностн колонок, после непродолжнтельного использования, были обнаружены следы ржавчины, то авторами были 
испюльзованы колснкн, изготовленные нз медной трубки, внутренним дняжетрсм 3 мм н длнной $7-8$ н.

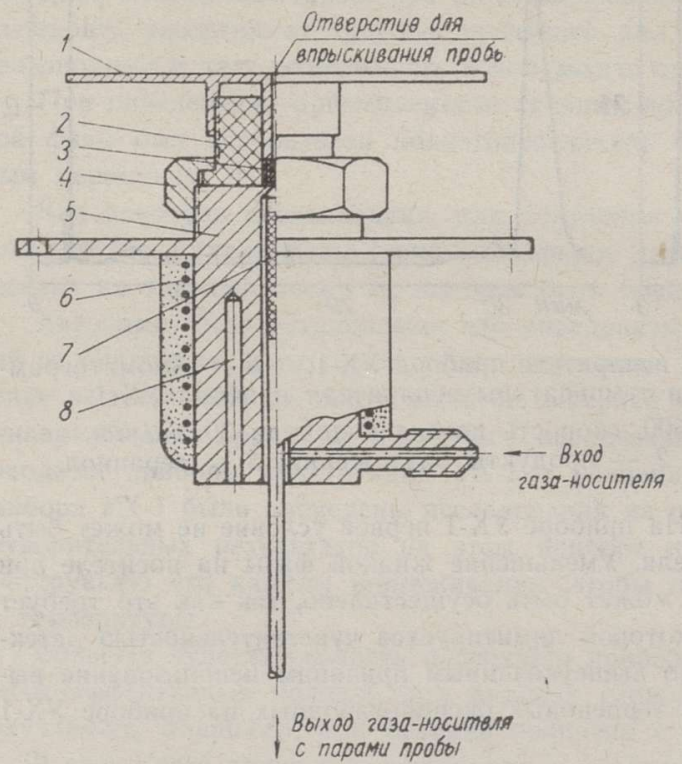

Схежа нспарителя. 1 - зажнжная втулка с отверстием для впрыскивания пробы и с охлаждающей пластинкой; 2 - фторопластовое уплотнение: 3 - пробка из силиконового каучука для впрыскивания пробы; 4 - зажнмная муфта для фторопластового уплотнення; 5 - корпус нспарнтеля; 6 - обмотка э.тектронагрева с нзоляцнєй; 7 - насадка нз серебряной сетки; 8 - карман для термопары.

Для поддержнвання необходимой величнны пламенн в детекторе прнбора приходнлось, в снлу малой скоростн газа при выходе из колонки, разбавлять прнненяемый в детекторе водород ннертным газом. В качестве газа-носителя использовалнсь аргон или углекнслота, расход газов определялся по ротаметру. Большая чувствительность прнбора позволнла использовать для анализа терпеновых спиртов стандартную колонку длиной 7 ж, заполненную насадкой из «Хромосорба $W$ », крупностью частиц $30-60$ меш, с нанесенным полиэтнленгликолем 4000 в количестве $4 \%$ от веса носителя при температуре $150^{\circ}$. При использованнн этой колонки при температуре $200^{\circ}$ не было обнаружено прнзнаков разложения гераннола. При температуре $150^{\circ}$ на этой же колонке нсследовалось влияние температуры испарителя на результаты анализа (см. рнс. $2 a$ н 26 ).

В качестве жидкой фазы применялись, кроме полиэтиленгликоля 4000 (ПЭГ), еще полиэфнры адипиновой кнслеты с гликолем (АПЭГ) и фталевой кнслоты с глнколем (ФПЭГ). Последние сннтөзировались по методике, приведенной Коршакон [21].

Для обработки инертного твердого носителя размельченный диатомнтовын кнрпнч Апрелевского завода, носитель ИНЗ-600 (размер зерен 0,25-0,50 мм) или «Хромо сорб $P_{\gg}$ (крупность частиц $30-60$ меш), кнпятили в концентрированной соляной кнслсте в течение 6 часов, промывали водой и снова кипятили в новой порции концентрнрованной соляной кислоты. Операцию повторяли $3-4$ раза. Носитель промывался дистиллированной водой до получения нейтральной реакции промывных вод и, погле прнбавления небольшого количества аммиачной воды, высушивался при температуре выше $200^{\circ}$. Затем высушенный носитель перемешивался с метанольным раствором $\mathrm{KOH}$, взятым в количестве 0,5-1\% KOH от веса носнтеля. Растворнтель удалялся выпариванием прн температуре $120^{\circ}$. Таким образом, предварнтельно обработанный носнтель рассеивался на фракцин размером зерен $0,16-0,20 ; 0,20-0,25 ; 0,25-0,31$, $0,31-0,50$ мм, которые нспользовались отдельно.

Для нанесения жидкой фазы необходимое ее количество растворяли в подходящем растворителе, объем которого был несколько меньше (около 10\%) объема носнтеля для данной колонки, после этого, при перемешивании в высоком стакане, к раствору прнбавлялся носнтель. В случае применення сннтезированных полизфнров раствор предварнтельно нейтралнзовался по фенолфталеину прнбавленнем раствора $\mathrm{KOH}$ 
9 спнрте до розовой окраски. Растворитель выпаривался сначала врапением стакана под нагревательной лампсй, пстом в вакууме до полного удалення следов растворителя.

Колонки заполнялись при помощи вибратора, после заполнення нм прндавали нужную форну. В целях стабилизации колонки ее продували током ннертного газа прн тенпературе, превышающей на $10^{\circ}$ рабочую температуру.

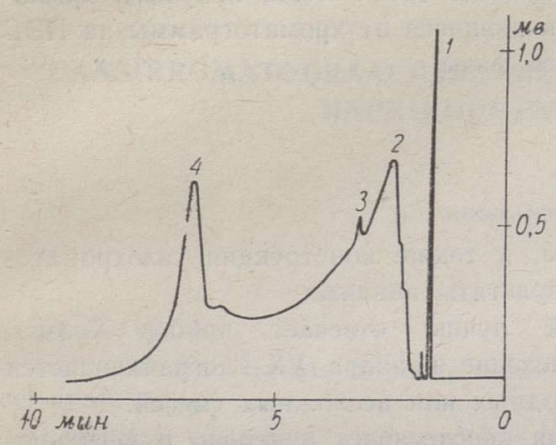

Рис. 3. Разложение гераниола в колонке. Прибор Хром-1, $T=200^{\circ}$, температура нс парителя $200^{\circ}$, скорость потока аргона 10 мл/мин, колонка $8 \%$ ПЭГ на ИН3-600, велнчнна пробы 0,005 н.л. 1 - эфнр; 2 продукты разложения; 3 - следы лнналоола; 4 - гераннол.

Колонкн с обработанной насадкой нз днатомнтового кирпича Апрелевского заॐона, носнтеля ИН3-600 н «Хромосорба $P$ » с нанесенным ПЭГ (15\% прн прнмененин

Рнс. 4. Разложенне гераннола и лнналоола в колонке. Прнбор Хром-1, $T=165^{\circ}$, температура нспарнтеля $180^{\circ}$, колонка $10 \%$ АПЭГ на ННЗ-600, жкорость потока аргона $15 \mathrm{~m} /$ жин, величнна пробы 0,005 мя. (Обозначенне см. рнс. 3.)

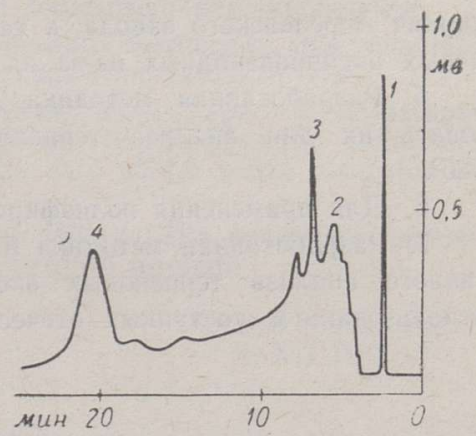

прнбора УХ-1 н $8 \%$ - лрн Хрон-1) являются прнгоднымн для анализа терпеновых слиртов прн тенпературе до $180^{\circ}$. Хроматограмма получается аналогнчно рнс. 26. При тежвературе $200^{\circ}$ наблюдается разложенне гераннола в колонке (рис. 3).
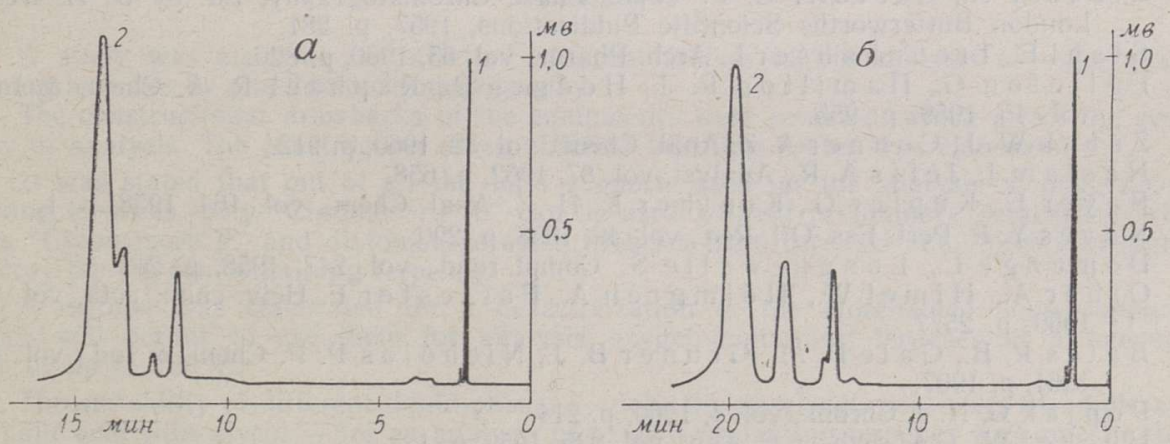

Pнс. 5. а - Хроматограмна сннтетического цитраля на прнборе Хрон-1. $T=160^{\circ}$, температура нспарнтеля $180^{\circ}$, колонка $8 \%$ ФПЭГ на ИНЗ-600, скорость потока аргона 15 жл/ жин. велнчнна пробы 0,002 н. 6 - Хроматограмма синтетнческого цитраля 4а прнборе Хром-1, $T=150^{\circ}$, температура испарення $180^{\circ}$, колонка $4 \%$ ПЭГ на «Хроносорбе $W »$, скорость потока аргона $15 \mathrm{~m} /$ мин, велнчнна пробы $0,002 \mathrm{M} .1$ - अфир: 2 - цнтраль А. 
С целью лучшего разделенил смесей терпеновых производных были использованы колонки, заполненные носителем ИНЗ-600 с нанесенными жидкими фазами АПЭГ и ФПЭГ, которые обладают большей полярностью, чем ПЭГ. Упомянутые колонки требуют большей стабилизации, чем колонки с ПЭГ. При нанесении жидкой фазы без предварительной нейтрализации свободных кислот происходит разложение гераннола и линалоола на насадке (рис. 4). Предварительная нейтрализация ускоряет также процесс стабилизации колонки. На колонке с нанесенным ФПЭГ были получены хрожатограммы синтетического цитраля (рис. $5 a$ ), отличаюшиеся ог хроматограммы на П1ЭГ (рнс. 5б), благодаря большой полярности жидкой фазы.

\section{Выводы}

1. Прнрода твердого носителя, температура, а также конструкция газохроматографов оказывают определенное влияние на результаты анализа.

2. Требованиям анализа сложных смесей лучше отвечает прибор Хром-1, обладающий высокой чувствительностью. Применение прибора УХ-1 ограничивается анализом низкокипящих терпеновых оксипронзводных или несложных смесей.

3. Новая конструкция камеры впрыскивания обеспечивает контроль и регулирование температуры камеры.

4. Для анализа териеновых оксипронзводных без предварительной дезактивации пригоден только «Хромосорб W». Отечественные носители ИНЗ-600, диатомитовый кнрпич Апрелевского завода, а также «Хромосорб $Р$ » непригодны для анализа терпеновых оксипроизводных из-за их разложения на вышеуказанных носителях.

5. Разработанная методика дезактивации носителей дает возможность использовать их для анализа терпеновых оксипроизводных при температуре не выше $180^{\circ}$.

6. Для применения полиэфнров необходимо их предварительная нейтрализация.

7. Разработанная методика и аппаратура обеспечивают проведенне высокоэффекзивного анализа терпеновых оксипроизводных газохроматографнческим методом $c$ использованнем доступных отечественных носителей.

\section{ЛИТЕ РА Т Р А}

1. Bernhard R. A., Ass J. Off. Agr. Chemists, vol. 40, 1957, p. 915 (PЖX, 17671, 1958).

2. J a nak J., Cvrka 1 H. Collect. Czech. Chem. Comm., vol. 24, 1959, p. 1967.

3. Liberty A., Cartoni G. P. Vapor Phase Chromatography, Ed. by D. H. Desty London Butterworths Scientific Publications, 1957, p. 281.

4. St a hl E., Tren $\mathrm{n}$ ha us er L. Arch. Pharm., vol. 65, 1960, p. 826.

5. Eg lint on G., H a mi it on R. J., Hodges R., R a phael R. A. Chem. \& Ind., vol. 45,1959, p. 955.

6. Zub y k W. J., C o n ner A. Z..Anal. Chem., vol. 32, 1960, p. 912.

7. H a s 1 a m J., J e f f s A. R., Analyst, vol. 87, 1962, p. 658.

8. B a y er E., K upfer G., Kruther K. H. Z. Anal. Chem., vol. 164, 1958, p. 1.

9. $\mathrm{N}$ a ves Y.-R. Perf. Ess. Oil Rec., vol. 49, 1958, p. 290.

10. Dom a nge L., L onguew a lle S. Compt rend., vol. 247, 1958, p. 209.

11. Of ner A., Himel W., Holmgren A., Forrester F. Helv. chim. acta, vol, 42, 1959 , p. 2577

12. B a tes R. B., G a le D. M., Gruner B. J., Nicholas P. P. Chem. \& Ind., vol. 47, 1961 , p. 1907.

13. P o p j a k G. N. J. Chrom., vol. 4, 1960, p. 214.

14. H ü ckel W., G el s c he r E. Ann., vol. 625,1959, p. 12.

15. Ru d o If f E. von. Can. J. Chem., vol. 39, 1961, p. 1.

16. Ascoli F., Crescenzi V. Chim. e. ind. (Milan), vol. 40, 1958, p. 724.

17. Klouwe n M. H., He i de R. ter. J. Chrom., vol. 7, 1962, p. 297.

18. Руденко Б. А., Кучеров В. Ф., Смнт В. А., Семенов кий А. В. Изв. AH CCCP, OXH, 1962, стр. 236.

19. Lennartz Th. Ber., vol. 76 B, 1943, p. 831. 
20. Лээтс К. В., Шумейко А. К., Розеноер А. А., Кудряшева Н. В., Пи л я в к а я А. И. ЖОХ, т. 27, 1957, стр. 1510.

21. Корш ак В. В. Общне методы синтеза высокомолекулярных соединений. М., Нзл. AH CCCP, 1953, стр. $445,446$.

\author{
Ннститут химии \\ Академии наук Эстонской ССР \\ Поступнла в редакцию \\ 4. XII 1963
}

\title{
GAASIKROMATOGRAAFILISE MIEETODI VÄLJATÖÖTAMINE TERPEENSETE HAPNIKUUHENDITE ANALUUSIMISEKS
}

\author{
K. Lääts, \\ keemiateaduste kandidaat
}

A. Erm

Resümee

Uuriti mitmesuguste faktorite mõju terpeensete hapnikuühendite gaasikromatograafilisel analüüsil.

Selgitati välja kasutatud seadmete konstruktsioonilised puudused, mis avaldavad mõju analüüsi tulemustele. Töötati välja otstarbekohase aurustaja konstruktsioon.

Leiti, et terpeensete hapnikuühendite analüüsiks kasutatud tahketest kandjatest sobib ilma eelneva töötlemiseta ainult «Chromosorb W», kuna «Chromosorb P» ja diatomiittellised Inzevski ning Apreljevski tehasest lagundavad terpeenseid hapnikuühendeid.

Töötati välja metoodika nimetatud tahkete kandjate desaktiviseerimiseks, mis võimaldab kasutada neid terpeensete hapnikuühendite analüüsiks kuni temperatuurini $180^{\circ} \mathrm{C}$.

Uuriti erinevate vedelate faaside (polüetüleenglükool, adipiinhappe ja ftaalhappe polüestrid glükooliga) kasutatavust ja leiti, et terpeensete hapnikuühendite analüüsiks sobivad adipiinhappe ja ftaalhappe polüestrid glükooliga vaid pärast nende neutraliseerimist.

Uurimise loppresultaadina konstrueeriti aparatuur ja töötati välja metoodika terpeensete hapnikü̈hendite täpseks analüüsiks gaasikromatograafilisel meetodil.
Eesti NSV Teaduste Akadeemia Keemia Instituut

\section{Saabus toimetusse}
4. XII 1963

\section{AN ANALYSIS OF OXYGEN-CONTAINING TERPENES BY GAS-LIQUID CHROMATOGRAPHY}

\author{
K. Lääts, A. Erm
}

\section{Summary}

A study was made of the effect of different factors in the analysis of oxygen-containing terpenes by gas-liquid chromatography.

The constructional drawbacks of the equipments were revealed, which affect the accuracy of analysis. The construction of an efficient injection heater was elaborated.

It was stated that out of all the solid supports used for the analysis of oxygen-containing terpenes, only "Chromosorb W" can be used without preliminary processing, whereas "Chromosorb P" and diatomaceus earth firebrick from Inzevski and Aprelevski plants destroy the oxygen-containing terpenes.

A method was elaborated for a desactivization of the aforenamed solid supports, which will permit to use them for analysis oxygen-containing terpenes at a temperature of up to $180^{\circ} \mathrm{C}$.

The suitability of different liquid phases - polyethyleneglycol, polyesters of adipic and phthalic acid with glycol - for an analysis of oxygen-containing terpenes was investigated, and the two last-mentioned proved suitable after neutralization.

Finally, the construction of an apparatus for an accurate analysis of oxygen-containing terpenes by gas-liquid chromatographic methods was elaborated. Academy of Sciences of the Estonian S.S.R.,
Institute of Chemistry
Received

Dec. 4th, 1963 